\title{
Sustainability considerations in the operation of Wastewater Treatment Plant 'Swarzewo'
}

\author{
Alina Dereszewska ${ }^{1, a}$ and Stanislaw Cytawa ${ }^{2}$ \\ ${ }^{1}$ Gdynia Maritime University, Department of Chemistry and cargo Commodity Science, Morska Str.81-87, 81-225 Gdynia, Poland \\ 'Swarzewo' Wastewater Treatment Plant, Wladyslawowska Str. 84, 84-120 Wladyslawowo, Poland
}

\begin{abstract}
The Wastewater Treatment Plant (WWTP) 'Swarzewo' plays a special role in the protection of coastal waters of the Baltic Sea area and the management of solid wastes in the region. This paper discusses several options implemented in the WWTP area in order to achieve sustainability. The first one was the inclusion of WWTP into municipal waste management plan to increase the biogas production and to reduce volume of organic waste in the region. Nowadays, daily production of about $2000 \mathrm{~m}^{3}$ of biogas is gained. The energy balance shows a considerable benefit from the co-fermentation of sludge with municipal organic wastes. The next goal was to obtain a favorable economical balance of energy and high level of pollution reduction. The last one was the involvement of local communities in a conscious segregation of waste 'at source'. For the purpose of this paper bio-energy production, nutrient elimination, composting, and research, have been selected as indicators of sustainable development. Furthermore, in this study the methods of nutrient recovery from wastewater were explored. Struvite precipitation and compost production were presented as an example of nutrient elimination with 'end of waste' production. Depending on the struvite precipitation conditions, recovery of $4 \mathrm{Mg}$ of phosphorous and $1,8 \mathrm{Mg}$ of nitrogen is possible to obtain annually.
\end{abstract}

\section{Introduction}

Protection of coastal areas from excessive pollution is a challenge for many countries [1,2]. The specificity of each region determines the system of sewage treatment and waste management, so that it could possibly correspond to the behavior principles of responsible, sustainable development. The Baltic Sea Coast is significantly burdened with pollution that is caused by intensive tourism and highly loaded wastewater fish industry. One of the most serious environmental problems of the region is eutrophication caused by excessive loads of nitrogen and phosphorus discharges of the water reservoirs. Nutrient compounds present in wastewater act as fertilizers. Those compounds, when excessive in their quantities in the sea environment, can disturb the ecological balance. The eutrophication devastates the ecosystem, hinders the use of marine resources and affects the recreational activities. The solution of this problem is strictly connected with the sustainability concept.

There is no consensus on the sustainability definition. Several concepts have been used to describe sustainability but a common principle is that sustainability should be seen in terms of the integration of three dimensions: environmental, economic and social [3-6]. Economic sustainability implies the incurrence of costs that should not exceed the benefits. Ecological sustainability refers to support its long-term development of environment through the protection of natural resources and reduction of emissions. Sustainability also has a social aspects. The social dimension is based on the education, which forms public awareness. In fact sustainable development can be achieved only in a community which feels that behind this development is responsible, understands the challenges and accepts the consequences of appropriate actions $[4,7]$.

In relation to the wastewater treatment system, the most important task is to protect aquatic life. Increasing the awareness (including the appropriate decision-makers) of the impact of sewage pollution on the Baltic Sea waters results in the increased emphasis on the consistent sustainable reconstruction of the wastewater treatment plants [2]. The adoption of low-cost wastewater treatment technologies is very important in the implementation of this strategy. It maximizes the efficiency of wastewater treatment, reduces the amount of consumed energy simultaneously (thereby reducing $\mathrm{CO}_{2}$ emissions) and seeks the minimization of waste generation. Furthermore the awareness of the local community must also be raising largely as well as bear the costs of wastewater treatment plant operating because it is exposed to the side effects of its work (eg. odors) [4,8,9]. In order to find the best way to sustainable region development it should be find a compromiseshould be found between the cost

$\overline{{ }^{a} \text { Corresponding author: a.dereszewska@wpit.am.gdynia.pl }}$ 
of waste water treatment and environmental benefit from reduction of the pollution of the Baltic water.

In this paper strategy for the operation of Wastewater Treatment Plant 'Swarzewo' (WWTP) based on the principles of sustainable development has been briefly described. The indicators of sustainability of particular relevance for the work of WWTP and the coastal region of the Baltic Sea were selected. Among them are both measurable indicators, (ie. the cost, energy saving, effluent parameters) and irrational outcomes, associated with the waste segregation propagation, education or scientific research were presented. The paper also presents the examples of applied specific technological solutions.

\section{Characteristic of the region and WWTP 'Swarzewo'}

The catchment area of the Wastewater Treatment Plant 'Swarzewo' includes land belonging to the Puck District and is the most northerly situated of the treatment plants in Poland. It has a significant impact on the protection of coastal waters of the Baltic Sea. The biological part of this treatment consist of the six SBR reactors (Sequential Batch Reactors) enable to removal of nutrients.

WWTP 'Swarzewo' was modernized in the years 2014-2016 in order to generate less wastes and produce more valuable products (compost and biogas). Among many changes, as a part of modernization digesters and cogeneration have been incorporated into the existing technological sequence, resulting in the production of biogas for electricity and heat. The modernization also included additional solutions for protection against excessive discharge of nutrients into the Baltic Sea. There was the oxygenation chamber for leachate from digestive chambers an additional secondary sedimentation tank, for treated sewage. In the summer months (July and August) sewage treatment plant purifies up to 15000 $\mathrm{m}^{3} /$ day, while during the remaining period - about 5000 $\mathrm{m}^{3} /$ day. About 95 percent of waste water is domestic, the rest is received from the fish industry, heavily loaded of fats and proteins.

The specificity of the Puck region is a production of large amount of municipal waste, including those that are susceptible to biological degradation. A significant amount of it is exported as mixed waste to distant landfills up to $60 \mathrm{~km}$. About $45 \%$ of waste produced by households is a biodegradable organic waste. If landfilled, then methane, carbon dioxide, hydrogen sulfide and other harmful gases are emitted into the atmosphere. Rains cause the formation of leachate polluting groundwater.

Coordinated cooperation with the Authorities responsible for protecting of the coastline led to the extension of the tasks of WWTP for solid waste utilization enable for fermentation. This solution is beneficial both for the regional units of public utilities, because it reduces transport of waste to distant landfills, and for the treatment plant which can thus increase the production of energy from biogas $[9,10]$.
The condition for the implementation of co-fermentation (fermentation sewage sludge and organic waste) is to educate inhabitants in the segregation of waste 'at source'. It involves detailed segregation conducted in households by the instruction drawn up by the waste customer [11].

\section{Indicators of sustainability}

Sustainability of wastewater treatment systems can be estimated through analysis of different indicators. Some of them (eg. energy saving, cost analysis, environmental impact) are possible to quantify, others are immeasurable. Many of indicators are listed in literature but sometimes self- defining of them is more effective than achieving a sustainability in region $[1,5]$.

Criteria of conducted in the WWTP sewage-waste management, for the sustainable development of the Baltic Sea region, can be summarized in the following points:

1. Minimizing, within an acceptable cost, impurities in the outflow.

2. The maximum recovery of nutrients and their conversion into a full-fledged product ('end of waste' philosophy).

3. The production of 'green energy' and commitment to self-sufficiency in energy.

4. Processing of waste being harmful to the region.

5. Education in the field of waste segregation and development using research.

6. Reduction of the effects burdensome to the local community (eg. odors).

The work was chosen the analysis of several aspects important for the region to achieve those objectives.

\subsection{Nutrient reduction and recovery}

Removal of nitrogen and phosphorus from wastewater is one of the priorities of WWTPs, since the presence of nutrients in the outflow contributes to eutrophication of the Baltic Sea. In addition, deposits of phosphate are intensively used as the main source for the production of industrial fertilizers. The amount of these minerals is limited which implies the need for the recycling of phosphorus [7]. To the WWTP flows an average of $296 \mathrm{Mg}$ on nitrogen and $43 \mathrm{Mg}$ of phosphorus per year. The nutrient concentration, allowed by standards in the outflow is $10 \mathrm{~g} / \mathrm{m}^{3}$ for nitrogen and $1 \mathrm{~g} / \mathrm{m}^{3}$ for phosphorus. It is difficult and costly to achieve these parameters. Exceeding these standards by $1 \%$, monthly is discharged additionally $15 \mathrm{~kg}$ of nitrogen and $1,5 \mathrm{~kg}$ of phosphorus. In summer, this value increases up to three times. Environmental penalties incurred by WWTP 'Swarzewo' for exceeding the limit of nutrients are even PLN 750.000 per year. Average concentration of nutrients in the effluent and the load of phosphorus and nitrogen discharged by treatment plant for the Baltic Sea annually is shown in Table 1. Data for 2016 are estimated on the basis of the results obtained after modernization, in March 2016. 
Table 1. The concentration of nitrogen $\left(\mathrm{C}_{\mathrm{N}}\right)$ and phosphorous $\left(C_{P}\right)$ in the effluent. The amount of nutrients supplied by the WWTP 'Swarzewo' annually to the Baltic Sea (N-load; P-load).

\begin{tabular}{|c|c|c|c|c|}
\hline year & $\begin{array}{c}\mathrm{C}_{\mathrm{N}} \\
{\left[\mathrm{g} / \mathrm{m}^{3}\right]}\end{array}$ & $\begin{array}{c}\text { N-Load } \\
{[\mathrm{Mg} / \text { year }]}\end{array}$ & $\begin{array}{c}\mathrm{C}_{\mathrm{P}} \\
{\left[\mathrm{g} / \mathrm{m}^{3}\right]}\end{array}$ & $\begin{array}{c}\text { P-Load } \\
{[\mathrm{Mg} / \text { year }]}\end{array}$ \\
\hline 2010 & 15.8 & 28.8 & 0.9 & 1.6 \\
\hline 2011 & 15.5 & 28.3 & 1.0 & 1.8 \\
\hline 2012 & 10.9 & 19.9 & 1.0 & 1.8 \\
\hline 2013 & 12.8 & 23.4 & 1.2 & 2.2 \\
\hline 2014 & 12.1 & 22.1 & 0.9 & 1.6 \\
\hline 2015 & 17.5 & 31.9 & 2.2 & 4.0 \\
\hline $\mathbf{2 0 1 6}$ & $\mathbf{6 . 0}$ & $\mathbf{1 1 . 0}$ & $\mathbf{0 . 8}$ & $\mathbf{1 . 4}$ \\
\hline
\end{tabular}

The majority of nitrogen is dissolved in wastewater as ammonium salts. In WWTP it is removed from the wastewater biologically in the nitrification / denitrification processes. The decisive role in its removal is fully controlled by of the concentration of ammonium compounds during the aeration process of activated sludge. Before the modernization, control process of wastewater treatment was carried out, as in most of this type of treatment plants, basis on timing control suited to the aeration of waste water volume. The studies conducted jointly with the Gdynia Maritime University have shown that this control often leads to incomplete removal of nitrogen or to unnecessary aeration [12]. Analysis of the results has led to a changes in the control system. After the modernization, nitrogen transformations are controlled by sensors of ammonia and nitrate nitrogen during process. With this change, the nitrogen concentration in the effluent drop down to $6 \mathrm{~g} / \mathrm{m}^{3}$, below the limit. Thus, the flow of nitrogen into the Baltic Sea can be reduced by up to three times compared to the state before upgrading.

The biological removal of phosphorus from wastewater is much harder to control. A large part of it is removed together with the excess sludge composted and sold as valuable products. An sustainable alternative to remove it is composting of excessive sludge [13]. Taking care of a high standard of composted organic material led to the production of certified compost which can be used as organic fertilizer in agriculture. In this way non-degradable waste from WWTP 'Swarzewo' are minimized to $2 \%$. When the new product appears on the market, produced from waste and complies with required standards criteria with no harmful effects on the environment and people, meets the criteria 'end of waste' philosophy [14]. Phosphorus is in a very large extent absorbed by sludge, but it is only partial remove of the phosphorus from wastewater. Finally, it's removing is performed chemically, using a ferric coagulant.

\subsubsection{Nutrient recovery research}

During the anaerobic process of sludge digestion is released a significant amount of nitrogen and phosphorus. Therefore, the post-fermentation leachate contains a high concentration of these elements (both nitrogen and phosphorus - up to $300 \mathrm{~g} / \mathrm{m}^{3}$ ). These leachate are returned to the chambers SBR and again cleaned. Oxidation of such large loads of nitrogen results in significant energy consumption (aeration) and difficults to obtain proper standards of wastewater discharged into the sea. It causes decrease in throughput of WWTP $[8,14]$.

Currently, research on the nutrient elimination from the leachate by precipitation of magnesium ammonium phosphate (struvite) is carried out. This method not only allows the removal of nutrients from wastewater, but also its recovery in the form of a compound with very desirable properties as fertilizer $[15,16]$. Struvite is precipitated by using a cheap secondary raw material (magnesium salt), thereby reducing the use of ferric coagulant to the process of phosphorus removal (approx. 250 t/year). Using traditional coagulant, significant amounts of iron is accumulated in the compost produced by the WWTP, which is disadvantageous in the process of fertilization. The use of the cheaper waste magnesium salt to struvite precipitation also reduces the costs associated with the purchase of coagulant (annual cost now stands at PLN 50 000).

At this stage the laboratory test were carried out and results are promising. Depending on the precipitation conditions recovery of $90 \%$ of phosphorous and $20 \%$ of nitrogen from the leachate were obtained. Selected results of the test are presented in Table 2.

Table 2. The percentage of phosphorous $\left(\mathrm{P}-\mathrm{PO}_{4}\right)$ and nitrogen $\left(\mathrm{N}-\mathrm{NH}_{4}\right)$ recovery depend on the $\mathrm{pH}$ and initial concentration of nutrients in some of leachates investigated.

\begin{tabular}{|c|c|c|c|c|}
\hline \multicolumn{2}{|c|}{$\begin{array}{c}\text { Initial } \\
\text { concentration } \\
\left(\mathrm{g} / \mathrm{m}^{3}\right)\end{array}$} & \multirow[t]{2}{*}{$\mathrm{pH}$} & \multicolumn{2}{|c|}{$\begin{array}{c}\text { Nutrient recovery } \\
{[\%]}\end{array}$} \\
\hline $\mathrm{P}_{-} \mathrm{PO}_{4}$ & $\mathrm{~N}-\mathrm{NH}_{4}$ & & $\mathrm{P}-\mathrm{PO}_{4}$ & $\mathrm{~N}-\mathrm{NH}_{4}$ \\
\hline \multirow[t]{3}{*}{120} & \multirow[t]{3}{*}{----- } & 7.5 & 30 & \multirow[t]{3}{*}{---------- } \\
\hline & & 8.5 & 17 & \\
\hline & & 9.5 & 72 & \\
\hline 105 & 550 & 9.3 & 79.2 & 21.6 \\
\hline 98 & 110 & 8.5 & 69 & ---- \\
\hline 315 & 412 & 8.5 & 74 & 24 \\
\hline 315 & 412 & 9.5 & 77 & 27 \\
\hline 330 & 504 & 9.5 & 90 & 22.1 \\
\hline
\end{tabular}

Simultaneously, the test with using the model of prototype device and leachate from fermentation chambers was carried on. Depends on crystallization conditions, struvite crystals with different size and form were obtained (Figure 1). Regardless of their size, struvite crystals exhibited good sedimentation properties. This is important from a technological point of view, since it reduces process time and makes it easy to separate the crystals from the leachate. 


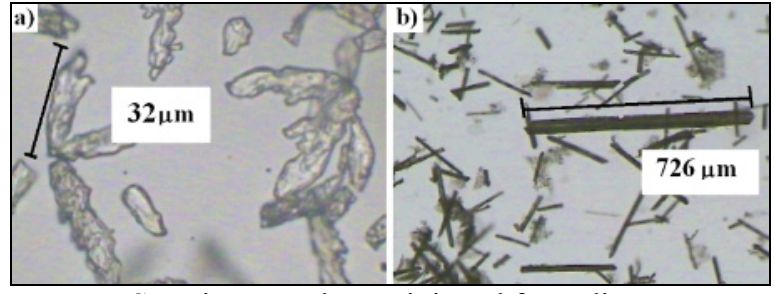

Figure 1. Struvite crystals precipitated from digestate leachate at $\mathrm{pH} 9.5 \mathrm{a}$ ) crystallization time $1 \mathrm{~h}$, concentration $\mathrm{P}_{-} \mathrm{PO}_{4} 315 \mathrm{~g} / \mathrm{m}^{3}$ b) crystallization time 48 $\mathrm{h}$, concentration $\mathrm{P}_{-} \mathrm{PO}_{4} 153 \mathrm{~g} / \mathrm{m}^{3}$.

Summarizing, the technology based on struvite precipitation offers the following benefits:

- Reduction of phosphorus and nitrogen return loads and in treated wastewater,

- Reduction of energy consumption,

- Reduction of ferric coagulants consumption,

- Prevention of struvite crystallization in pipes,

- Simple and quick struvite precipitation process,

- Obtaining of bio-available and slow-release fertilizer

- Reduction of fossil minerals consumption (eg. apatites).

The expected amount of post-fermentation leachate in the WWTP 'Swarzewo' is $60 \mathrm{~m}^{3} /$ day. Assuming that the same efficiency as in the preliminary study will be achieved, it is possible to recover $4 \mathrm{Mg}$ of phosphorus and $1.8 \mathrm{Mg}$ of nitrogen per year. The costs and expenses associated with the production of struvite include, as appropriate:

Savings: coagulant consumption, the elimination of aeration; sale of struvite;

Expenditure: a magnesium salt; $\mathrm{pH}$ adjustment, depreciation, electricity

This analysis indicated that financial gain for the WWTP will be approximately PLN 40000 , The profit is not significant, however, the most important is environmental effect and the possibility of utilizing the resulting waste.

After detailed study and obtaining the appropriate certification, the precipitated struvite can be a valuable bio-fertilizer. In this case, it will be the next WWTP product which meets the criteria for 'end of waste'.

\subsection{Energy}

Wastewater treatment is a process demanding high energy consumption [9,10]. WWTP 'Swarzewo' consumes approx. $2500 \mathrm{MWh}$ of electricity per year. One of the ways to optimize energy consumption in the plant is the implementation of the fermentation process for biogas production. It is possible to co-digest selectively segregated municipal waste with sludge from sewage treatment and some industrial waste (ie. grease from fish industry, agricultural waste). There are two co-generators installed by the treatment plant, which convert the resulting biogas into electricity and heat (1: 1). Part of the biogas is burned directly in boilers. Quantity of biogas obtained in the first six weeks of working chambers, and the quantities of energy (heat and electricity) obtained in this way is shown on the Figure 2.

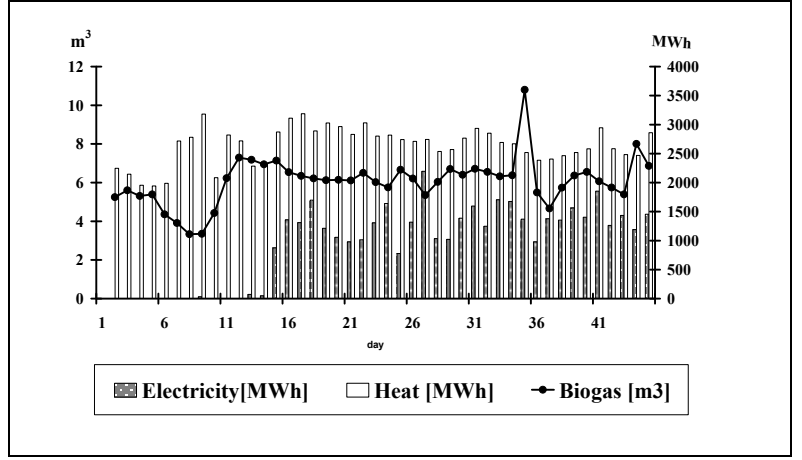

Figure 2. Biogas and energy production in WWTP 'Swarzewo' after modernization (1.03-18.04.2016)

The energy balance of WWTP shows significant benefits from the co-fermentation of sludge with municipal waste. In this way an average of $1925 \mathrm{~m}^{3}$ of biogas is produced daily, which is converted into $12,5 \mathrm{MWh}$ (total - heat and electricity). It is estimated that the plant can become energy self-sufficient while maintaining the same level of fermentation during the whole year and can produce $4560 \mathrm{MWh} /$ year of energy. It should be taken into account, however, after modernization, a number of new devices was installed and energy consumption increase.

The planned target capacity of digestive chambers is $8000 \mathrm{~m}^{3}$ of biogas / day and is largely dependent on collected wastes to co-digestion. The possibility of codigestion of waste is also a factor for segregation of garbage in the region. It mobilizes inhabitants generating waste to extract one stream fit for fermentation. Catchment area of treatment plant includes 32 thousand population, each of them produces approximately $200 \mathrm{~kg} /$ year of green waste. The waste, after a suitable separation, can be incorporated into cofermentation or to produce compost. Part of the waste for fermentation passes from the fish industry. These are high-energy waste (grease, protein) troublesome for manufacturers, and favorable for biogas production. The WWTP 'Swrzewo' contract is to acquire, for the purposes of the fermentation, $1500 \mathrm{Mg}$ per year of this type of waste.

The WWTP 'Swarzewo' is capable of receiving $26.000 \mathrm{Mg}$ of organic waste/year, thus it is facilities for the production of energy for own needs and even to sell the surplus. First quarter of the year of operating modernized WWTP showed that proceeds from the selective collection of waste represents only $4 \%$ of potential. Acquisition of organic waste is therefore a fixed point in the development plans of WWTP.

Energy balance of wastewater treatment plants can also be improved by reduction of energy consumption in the process of aeration. Wastewater treatment is based on the mineralization of organic compounds by the activated sludge microorganisms. This process requires a sufficient amount of oxygen delivery to microorganisms and involves a considerable energy consumption. Due to the fact that the oxidation of nitrogen compounds, is the longest mineralization process, this parameter can be used as an indicator 
of the time required for their purification. As already mentioned the use of nitrogen probe eliminates unnecessary aeration of wastewater and thereby improves energy saving. Pilot studies have shown that using control system of the purification process, based on indications of ammonium and nitrate nitrogen, the consumption of energy for aeration can be reduced about $10-15 \%$ [12]. Another important change in the process of wastewater treatment, resulting after the nitrogen sensors using, is a significant prolongation of denitrification phase. The process do not requires aeration, and consumes relatively small amounts of energy, but reduce the capacity of the single reactors by increase of the retention time in the reactor. For this reason two additional reactors were built to increase the capacity of the entire plant.

\subsection{Social dimension}

\subsubsection{Waste segregation and composting}

The results of sewage treatment is waste in the form of excess sludge as a source of carbon- organic fertilizer and it is rich of valuable substances. The sludge mixed with selected organic waste can be processed into a valuable compost [2]. Wastewater treatment plant produces compost under the name of 'Ulkomp' with certified quality since 2006 . The low price is also an encouragement for local communities to include them in the segregation system. The obtaining a compost that meets all the requirements excludes the use of contaminated input materials. Such purity can be provided only by segregation of waste 'at source' at homes.

WWTP runs an educational campaign since 2001. The detailed instructions of segregation organized among the inhabitants of the region were developed. The campaign has enjoyed great popularity among the inhabitants, also contributed to the growth of ecological awareness. After the modernization of WWTP the waste are supplied by authorized individuals and the WWTP was joined to the system of waste management. The area covered by the system of waste segregation involves 104000 of inhabitants (the average value takes into account the visiting tourists). Basis of the quantity of waste collected it can be concluded that $10 \%$ of the population is involved in the segregation system.

The cooperation with the local community also contributed to greater acceptance of WWTP, which belongs to the object to some extent onerous. The modernization included the reduction of odors, which are burdensome to the local community and have negative influence on tourism development in the region. The artificial aeration was applied to composting for accelerate the processes, also a number of filters to eliminate odors were installed.

\subsubsection{Education and research}

There are several research and development project on wastewater treatment. Pro-ecological profile of company resulting in the opening of the new technologies. An important aspect is the cooperation with the academic community. It is known, that this collaboration have an impact on both: regional innovation and academic research. to regional innovation $[17,18]$. Exchange of experience between operators of the WWTP 'Swarzewo' and researchers from universities ( Technical University of Gdansk and Gdynia Maritime University), results in the search for new solutions, especially designed to protect the Baltic Sea environment. Moreover, there are also students included in the research work This allows them to confront the theoretical knowledge acquired at university with its practical application. Preliminary modeling studies allow estimation of both the benefits and expenses resulting from the possible implementation of new solutions. The discussed earlier pilot studies are the example of the WWTP 'Swarzewo' co-operation with Gdynia Maritime Academy. Those studies are aimed at assessing the possibility of incorporation of the prototype device for struvite precipitation and purification in the technological line of wastewater treatment.

\section{Summary}

The need to be more efficient with the use of resources and with environment protection has become a important issue in water treatment management. Sustainability issues as the energy balance, carbon dioxide emissions, total chemical usage, the nutrients and other type of contamination present in effluent are now of critical importance in the design and operation WWTPs. It results with a number of changes in wastewater management, including the development of new technologies for recovery of nutrients and energy. On the other hand WWTPs managers have to regard to economic aspects and find the balance between high level of wastewater treatment and costs. The sustainability also has social aspects. Local community acceptance is very significant considering that largely they bear the costs of wastewater treatment and modernization of the plant. Very important is the education of the local community to understand the impact that has on the environment and WWTP and thus the meaning of the costs incurred.

This paper discussed several sustainable considerations implemented in wastewater treatment plant 'Swarzewo' or planned for its future development. Treatment plant was modernized, adapting to the processing of organic waste. The installation is based on obtaining detailed waste-selected 'at source' by the local inhabitants. The co-fermentation of sludge from municipal waste generated benefits as a decrease of energy consumption, and is promising to achieve energy self-sufficiency in WWTP. In this area WWTP seeks to maximize the use of their own waste. 
Cooperation of WWTP operators with Academic, and results of research work carried out, point the way to further changes.

\section{References}

1. A.N. Bdour, M.R. Hamdi, Z. Tarawneh, Desalination 237 (2009)

2. J. Pubule, A. Blumberga, F. Romagnoli, D. Blumberga, J. Clean. Prod. 88 (2015)

3. S.Ch. Jhansi, S.K. Mishra, J. Sust. Develop. 10,1 (2013)

4. H. E. Munga, J. R. Mihelcic, J. Environ. Manag. 88 (2008)

5. A. J. Balkema, H. Preisig, R. Otterpohl, F.J. Lambert, Urban Water, 4 (2002)

6. R. Reardon, S. Deslauriers, R. Samstag, L. Baumberger, Florida Wat. Res. J. 1 (2011)

7. U. Wiessmann, I.S. Choi, E. Dombrowski, Fundamentals of Biological Wastewater Treatment, (WILEY-VCH Weinheim, Germany, 2007)

8. I. Bodik, M. Kubaska, Environ. Prot. Eng. 39, 2 (2013)

9. O. Novak, P. Enderle, P. Varbanov, J. Cleaner Prod. 88 (2015)

10. K.Y. Chae, J. Kang Energy Conversion and Management 75 (2013)

11. T.H. Christensen (Ed), Solid Waste Technology \& Management, (Blackwell Publishing Ltd, Chichester UK, 2011)

12. A. Dereszewska, S. Cytawa, Ekonomia i Zarządzanie 4, 1 (2012) (in Polish)

13. W. Mo, Q. Zhang, J. Environ. Manag. 127 (2013)

14. H. Saveyn, P. Eder, IRC Scientific and policy reports Technical Proposal EU ( 2014)

15. L.E. de Bashan, Y. Bashan, Water Res. 38 (2004)

16. Y. Ueno, M. Fujii Environ. Technol. 22, 11 (2001)

17. R. Ponds, F. Oort, K. Frenken, J Econ. Geogr. 1 (2009)

18. I.Ramos-Vielba, M.Fernandez- Esquinas, E. Espinosa de los Monteros, Scientometrics 84 (2010) 